life, and optimise patients' outcomes and clinical shared decision-making is a priority. Patient Reported Outcome Measures (PROMs) are used in healthcare to understand the impact of symptoms on people's quality of life. Electronic capture of PROM data (e-PROMS) are an efficient way of collecting PROM data and can minimise patients' burden.

Aim This study aims to establish the impact of trauma on patients' quality of life and to explore views on using e-PROMs to support clinical care and research.

Methods In-depth semi-structured one-to-one interviews were conducted with (i) TBI survivors and family members/carers; (ii) healthcare professionals/researchers working in trauma related clinical areas; and (iii) members from third sector organisations who support trauma patients and their families/ carers.

Results Preliminary results from 19 participants show using PROMs contributed to focus clinical consultations on issues deemed important to patients, including memory loss, anxiety, and lack of concentration. E-PROMS were considered flexible and timesaving and a valuable way of evaluating ongoing symptoms and their impact on quality of life when consulting with clinicians. Patients' mental health, type of injury, physical impairments, and changes in personality were considered as key features for inclusion in e-PROMs. Over and underreporting, lack of insight, cognitive and communication problems and lack of internet access, (especially among older patients), were considered barriers to using e-PROMs. Suggested features to facilitate use, included: easy to use, short length, conciseness, and lay language easily understood by trauma patients.

Conclusion The electronic capture of PROMs was found to be an acceptable way of reporting patients' symptoms. Particular attention should be paid to the inclusion of specific measures in future e-PROMs system, such as patients' ongoing mental health.

\section{P30 \#CRISISTEAMFAIL: TWITTER ANALYSIS TO ENRICH UNDERSTANDINGS OF MENTAL HEALTH CRISIS SERVICES}

Natasha Chilman, Nicola Morant, Bryn Lloyd-Evans, Jane Wackett, Sonia Johnson. University College London, London, UK

\subsection{6/bmjopen-2019-QHRN.64}

Background Analysis of Twitter data is a relatively new and developing form of qualitative health research. It allows access to how issues and experiences are socially shared and constructed amongst communities of health service users and providers, in ways that traditional or individual-based qualitative methods may not. In the UK, Crisis Resolution Teams aim to provide intensive home-based support to adults in mental health crisis. However, there are known problems with user satisfaction, and wide variations in implementation.

Aim To explore how Crisis Resolution Teams were discussed on Twitter and compare this with data collected via interviews and focus groups in a related study. ${ }^{1}$

Methods Twitter's advanced search function was used to retrieve relevant Tweets on Crisis Resolution Teams (20102018). A form of thematic analysis was conducted on 500 relevant randomly selected Twitter posts. Principles of refutational synthesis were applied to compare themes with those identified in interviews and focus groups.
Results The most popular 'hashtag' search term was '\#CrisisTeamFail'. Negative comments about Crisis Resolution Teams were found in $40.8 \%$ of Tweets, principally relating to access and quality of care. There were some overlaps between themes identified in both datasets, including the importance of rapid access to care and planned discharges. However, views expressed on Twitter were generally more critical than those obtained via face-to-face methods. This may be because people post about experiences with mental health services as they happen, and because Twitter communities include individuals who are less engaged with services.

Conclusion By looking at stakeholder views expressed on social media alongside traditional qualitative methods, researchers can capture a wider spectrum of opinions than with one method alone. Twitter can be a valuable resource for future health research which could feed into improving user engagement and collaboration in service design and improvement.

\section{REFERENCE}

1. Morant N, Lloyd-Evans B, Lamb D, et al. Crisis resolution and home treatment: stakeholders' views on critical ingredients and implementation in England. BMC Psychiatry 2017;17(1):254.

\section{P31 FROM FIGHTING THE SCOURGE TO EVERYDAY MANAGEMENT OF CANCER RISK: A FOUCAULDIAN ARCHAEOLOGICAL STUDY}

CF Brooks. University of Southampton, Southampton, UK

\subsection{6/bmjopen-2019-QHRN.65}

Background Studies of publicly available cancer information (CI) focus upon the provision of CI at specific times in history $^{1-2}$ or more recently patient preferences and use of electronic resources. ${ }^{3}$ As such, there is little research exploring the changing representation of cancer through early to electronic forms of CI.

Aims The aim of this paper is to present theoretical, methodological and epistemological insights from a qualitative study using Foucault's archaeological approach ${ }^{4}$ combined with the theoretical lens of medicalization ${ }^{5}$ to investigate the changing representation of cancer through CI (19342010), and consider their implications to current understandings of CI.

Methods Adopting a purposive sampling approach, archival and electronic CI were collected from a variety of sources, including the Wellcome Library, British Library, National Archives, GP surgeries and cancer charity websites.

Results Analytical findings reveal five thematic shifts, showing how increasing responsibility for the management of cancer risk and promotion of health has been placed upon the imagined reader ${ }^{\prime 6}$ of $\mathrm{CI}$ :

- the emergence of cancer as a scourge involving the combined efforts of medical professionals and the public to 'fight' (1934-1947).

- the moral pursuit of life saving (1948-1959).

- smoking, lung cancer and engaging in risky behaviours (1960-1978).

- individualism and the emergence of a regulatory consumer (1979-1999).

- everyday management of cancer risk and promotion of health (2000-2010). 
Conclusions Through enabling examination of the changing relations between the representation of cancer and the social, economic and political contexts within which they are embedded, Foucault's archaeological approach provides an innovative and valuable tool to understand contemporary conceptualisations of cancer, responsibility and risk as well as different forms of CI.

\section{REFERENCES}

1. Berridge V. Medicine, public health and the media in Britain from the nineteen-fifties to the nineteen-seventies. Historical research 2009;82:360-373.

2. Toon E. 'Cancer as the General Population Knows It':: Knowledge, Fear, and Lay Education in 1950s Britain. Bulletin of the History of Medicine 2007;81:116.

3. Bluethmann SM, Coa KI, Alfano CM, et al. Electronic health information exchange opportunities for self-management of care: responses from older adults with and without cancer history in the United States. Current oncology reports 2018;20:30.

4. Foucault M. The Archaeology of Knowledge 1997. London: Routledge.

5. Conrad P. The medicalization of society: On the transformation of human conditions into treatable disorders. JHU Press, 2007.

6. Crawshaw P. Governing the healthy male citizen: Men, masculinity and popular health in Men's Health magazine. Social Science \& Medicine 2007; 65: 1606-1618.

\section{P32 USING SOCIAL MEDIA AS A RECRUITMENT STRATEGY TO RECRUIT PATIENTS, GPS AND PHARMACISTS}

CF Brooks, CB Matheson-Monnet, A Argyropoulos. University of Southampton, Southampton, UK

\subsection{6/bmjopen-2019-QHRN.66}

Background Social media platforms occupy an increasingly significant role in providing learning and support for people to share healthcare experiences, ${ }^{1}$ yet little is known about their potential as participant recruitment avenues into health research. $^{2}$

Aim To develop understanding of the role of social media as a recruitment tool, this paper presents conceptual and methodological insights, as well as early findings from a study using social media alongside traditional recruitment pathways, ${ }^{1}$ to explore patient, General Practitioner and Pharmacist experiences of the local implementation of a national led digital technology. Methods Using a combined recruitment strategy comprising of social media and traditional recruitment pathways, patients, General Practitioners and Pharmacists are being recruited into a mixed method study, involving online surveys and telephone interviews, to explore their experiences of the local implementation of a national led digital technology.

Results Key insights include:

- Methodological design, development and implementation of a social media recruitment tool

- Barriers and enablers of using social media in comparison to traditional recruitment pathways

- Complexities of context: using a recruitment tool with an international reach to recruit locally

- Early exploratory findings and relationship to recruitment strategy

- Engagement and participation of different social media users: patients, General Practitioners and Pharmacists

- Implications for future research using social media as a recruitment tool.

Conclusions Key insights can contribute towards learning about the use of social media as a recruitment tool in health research involving digital technologies and consideration of complex interrelated methodological, contextual, relational, ethical and participation issues.

\section{REFERENCE}

1. Lupton D. 'It just gives me a bit of peace of mind': Australian Women's use of digital media for pregnancy and early motherhood. Societies 2017;7:25.

2. Arigo D, Pagoto S, Carter-Harris L, et al. Using social media for health research: Methodological and ethical considerations for recruitment and intervention delivery. Digital Health 2018;4:2055207618771757.

\section{P33 LIFE CYCLE OF HOMELESS: THE ROLE OF INTERPERSONAL RELATIONSHIPS TO HEALTH PRACTICES FOR DRUG USE}

Bachelor Marilia Ignacio De Espindola, Eroy Silva, Alessandra Bonadio, Ana Regina Noto. Universidade Federal de São Paulo, São Paulo, Brazil

\subsection{6/bmjopen-2019-QHRN.67}

Background To underlie new practices towards health promotion and well-being for homeless people and drug users, it is necessary to broaden the focus to interpersonal relationships throughout their life cycle. The Community Treatment is an innovative approach, as it proposes a change in perspective. Few studies have highlighted the process of human development and interpersonal relationships as a resource for new health practices.

Objectives To understand how interpersonal relationships and substance use are modified throughout the life cycle of homeless people in urban regions of São Paulo.

Methods This study followed a qualitative methodology and took place in the biggest city of Brazil, São Paulo, in 2017/ 2018. Three approaches were used: participant observation, formal interviews with key informants $(n=19)$ and homeless adults substance users $(n=14)$ using the timeline technique, with a total sample of 33 participants. All interviews were audiotaped and observations were registered in field diaries. The audio files were full transcribed and submitted to content analysis. All procedures were aligned to COREQ (Consolidated Criteria for Reporting Qualitative Research) and SRQR (Standards for Reporting Qualitative Research) guidelines.

Results Findings of the timeline technique and observational study show that the life cycle of homeless people and substance users are marked by several family bonds broken in two moments: childhood and adolescence. Living in the streets and drug use are connected with these broken ties. Themes related to LGBTT experiences appeared with considerable frequency and are also connected to these ruptures.

Conclusions Triangulation of data indicate that it is necessary to consider these broken bonds when creating new interventions for homeless drug users. The Community Treatment is an approach that considers all vulnerabilities found in the life cycle of this populations.

\section{P34 PARTICIPATORY RESEARCH METHODS IN EVIDENCE BASED LOCAL EMPOWERMENT FOR THE IMPROVEMENT OF ROMA HEALTH}

Gergely Papp. PAD Foundation for environmental justice, Budapest, Hungary

10.1136/bmjopen-2019-QHRN.68

In Hungary - as in other European countries - Roma experience significantly worse health outcomes than the general population. Limited access to health care services does not fully explain this gap in the Roma health status. Social and environmental determinants such as bad housing condition, limited 